\title{
COMPORTAMENTO DA LARANJEIRA 'PÊRA' SOBRE CINCO PORTA-ENXERTOS EM ECOSSISTEMA DE TABULEIROS COSTEIROS, UMBAÚBA-SE ${ }^{1}$
}

\author{
ROOSEVELT MENEZES PRUDENTE², LUIZ MÁRIO SANTOS DA SILVA², ALMIR P. DA CUNHA SOBRINHO²
}

\begin{abstract}
RESUMO - Em experimento instalado em 1984 no Campo Experimental de Umbaúba-SE, com delineamento em blocos casualizados, avaliou-se a potencialidade da laranjeira 'Pêra' [Citrus sinensis (L.) Osb.], clone $\mathrm{D}_{6}$, enxertada sobre cinco porta-enxertos. A análise estatística das médias dos dados do $9^{\circ}$ ao $13^{\circ}$ ano do plantio permite concluir que as seleções do limoeiro 'Volkameriano' (C. volkameriana Ten. \& Pasq.), 'Catânia 2' e 'Palermo', os limoeiros 'Cravo' (C. limonia Osb.) e 'Rugoso da Flórida' ( $C$. jambhiri Lush.) e a tangerineira 'Cleópatra' (C. reshni Hort. ex Tan.) apresentaram comportamentos semelhantes quanto à produtividade, percentagem de suco e teor de sólidos solúveis totais, evidenciando que o 'Catânia 2', 'Palermo' e 'Cleópatra' tiveram eficiência similar ao ‘Cravo' e 'Rugoso', porta-enxertos estes mais utilizados nas regiões citrícolas de Sergipe e litoral norte da Bahia.
\end{abstract}

Termos para indexação: Citrus, copa, produtividade, qualidade do fruto.

\section{BEHAVIOR OF PERA ORANGE ON FIVE DIFFERENT ROOSTOCKS IN BRAZILIAN COASTAL TABLELAND ECOSYSTEM}

\begin{abstract}
In an experiment set in a field in 1984 at the Experiment Station of Umbauba-SE, was studied the behavior of 'Pera' sweet orange [Citrus sinensis (L.) Osbeck], clone $\mathrm{D}_{6}$, grafted on five rootstocks in a soil of Brazilian northeast coastal tableland ecosystem. The data from the $9^{\text {th }}$ to the $13^{\text {th }}$ year, after planting, indicated that the rootstocks - 'Rangpur' lime (Citrus limonia Osb.), 'Volkamer' lemon (C. volkameriana Ten. \& Pasq.), 'Catania 2' and 'Palermo' selections, 'Florida Rough' lemon (C. jambhiri Lush.) and 'Cleopatra' mandarin (C. reshni Hort. ex Tan.) did not show statistic difference related to productivity, juice percentage TSS, giving evidence that the rootstocks 'Catania 2', 'Palermo' and 'Cleopatra' can be used with the same performance of 'Rangpur' lime and 'Rough' lemon, the most grafted in Sergipe and north coast of Bahia state citricultures fields.

Index terms: Citrus, scion/rootstocks, productivity, fruit quality.
\end{abstract}

\section{INTRODUÇÃO}

Em Sergipe, estima-se que $90 \%$ dos pomares são de laranjeira 'Pêra' enxertada sobre os limoeiros 'Cravo' e 'Rugoso da Flórida', respectivamente, $55 \%$ e $40 \%$, complementados pelos porta-enxertos limoeiro ‘Volkameriano' e tangerineira 'Cleópatra'. Esses porta-enxertos são recomendados aos citricultores e viveiristas, em decorrência de resultados parciais de pesquisa e observações de campo (Trindade et al., 1989).

Para uma variedade-copa proporcionar o máximo de produtividade, é necessário que, além dos tratos culturais adequados, haja uma perfeita integração com o porta-enxerto (Pompeu Júnior et al., 1978). Esses autores também supõem que o 'Cravo' não satisfaz às necessidades de todas as copas, havendo porta-enxertos que atendem melhor às exigências específicas de uma dada variedade.

Salibe (1987) destaca a significativa participação do porta-enxerto na combinação, influenciando nas características da copa, tais como o crescimento, a produção e a resistência à seca e ao frio. Pompeu Júnior (1991) foi mais além ao assegurar que "o porta-enxerto induz à copa alterações no seu crescimento, precocidade de produção, época de maturação e peso dos frutos, permanência dos frutos na planta, capacidade de absorção , síntese e utilização de nutrientes, tolerância à salinidade, resistência à seca e ao frio, resistência ou tolerância a moléstias e pragas, além de outros".

Dada a escassez de resultados sobre a potencialidade das combinações copa/porta-enxertos recomendadas para a região citrícola de Sergipe, o presente trabalho objetivou estudar o comportamento produtivo e vegetativo de cinco diferentes combinações submetidas às mesmas condições de ambiente físico e de manejo.

\section{MATERIAL E MÉTODOS}

O experimento foi instalado em julho de 1984 e conduzido sem irrigação, no Campo Experimental de Umbaúba-SE, da Embrapa Tabuleiros Costeiros, em solo do tipo Podzólico Acinzentado eutrófico com fragipan $\mathrm{Tb}$ A fraco, textura média/argilosa fase floresta subperenifólia e com relevo plano (Cintra, 1997). O clima é quente e úmido, tipo As', classificação
Köppen (clima tropical chuvoso, com verão seco), altitude de 109 m e precipitação média anual de 1.263,6 mm, com maior concentração nos meses de abril a setembro (Tabela 1).

Utilizou-se como copa a laranjeira 'Pêra' [Citrus sinensis (L.) Osb.], clone $\mathrm{D}_{6}$, enxertada nos limoeiros 'Cravo' (Citrus limonia Osb.), 'Rugoso da Flórida' (Citrus jambhiri Lush.), 'Volkameriano' (Citrus volkameriana Ten. \& Pasq.), seleções Palermo e Catânia 2 e tangerineira 'Cleópatra' (Citrus reshni Hort. ex Tan.), espaçados de $7 \mathrm{~m}$ x 3,5 m, arranjados em blocos ao acaso, com três repetições e quatro plantas por parcela.

As plantas receberam os tratos culturais necessários ao seu bom desenvolvimento.

Foram coletados dados de produção (peso total), dimensão da planta (diâmetro e altura da copa) e qualidade do fruto (peso médio do fruto, porcentagem de suco, teor de acidez e de sólidos solúveis totais). Com os dados de produção e densidade do plantio, foi estimada a produtividade ( $\mathrm{t} / \mathrm{ha}$ ) dos porta-enxertos. Utilizando-se das médias do diâmetro e da altura das copas, calculou-se o volume médio das plantas com a fórmula de Mendel, citada por Figueiredo et al. (1981): $V=2 / 3 \pi . R^{2}$. $\mathrm{H}$, onde: $\mathrm{V}=$ volume da copa $\mathrm{R}=$ raio médio; $\mathrm{H}=$ altura da copa. $\mathrm{O}$ índice de eficiência foi calculado dividindo-se a média da produção de cada combinação pelo respectivo volume de copa. A percentagem de sólidos solúveis totais (SST) foi determinada em refratômetro de campo, ajustandose os dados para a temperatura ambiente. A acidez total titulável (ATT) foi calculada por titulação com $\mathrm{NaOH}$ a $0,1 \mathrm{~N}$, tomando-se $25 \mathrm{ml}$ de suco e a fenolftaleína como indicador.

Os resultados foram submetidos à análise de variância aplicada às médias, comparadas pelo teste de Tukey, a 5\% e a 1\% de probabilidade.

\section{RESULTADOSEDISCUSSÃO}

A Tabela 2 mostra os dados da produtividade e peso médio dos frutos e os resultados das análises estatísticas. As produtividades médias da laranjeira 'Pêra' sobre os cinco porta-enxertos não diferiram significativamente, no período 1993 - 97. Constatou-se também que o ‘Cravo' e o ‘Rugoso', os mais utilizados nas regiões citrícolas de Sergipe e da Bahia, apresentaram semelhante comportamento produtivo por quase todo o período, exceto nos anos de 1993 e 1994, quando alternaram suas

\footnotetext{
${ }^{1}$ (Trabalho 171/2002). Recebido: 15/07/2002. Aceito para publicação: 06/02/2004.

${ }^{2}$ Eng.-.Agr ${ }^{\text {on }}$., M.Sc. Emdagro, contrato Embrapa/Emdagro, Av. Beira-Mar, 3250, Caixa Postal 44, fone 079)226-1349, CEP 49001-970, Aracaju - SE. e-mail: prudente@cpatc.embrapa.br e lmario@cpatc.embrapa.br.

${ }^{3}$ Eng. Agr ${ }^{\text {rn }}$, M.Sc. Embrapa Mandioca e Fruticultura, Rua Embrapa, s/n, Caixa Postal 007, CEP 44380-000, Cruz das Almas-BA. e-mail: almir@ cnpmf.embrapa.br.
} 
TABELA 1 - Dados pluviométricos mensais, no período de 1992-1997. Embrapa Tabuleiros Costeiros. Umbaúba-SE

\begin{tabular}{rrrrrrrrrrrrrr}
\hline Ano & Jan & Fev & Mar & Abr & Mai & Jun & Jul & Ago & Set & Out & Nov & Dez & Totais \\
\hline & & & & & & & mm & & & & & \\
1992 & 149,4 & 210,4 & 162,8 & 66,4 & 74,0 & 207,0 & 209,6 & 82,6 & 189,2 & 18,2 & 113,2 & 34,4 & $1.517,2$ \\
1993 & 7,6 & 1,4 & 25,4 & 120,8 & 58,0 & 219,2 & 96,6 & 211,4 & 74,2 & 101,6 & 12,6 & 37,8 & 966,6 \\
1994 & 7,8 & 110,4 & 57,0 & 78,4 & 158,4 & 394,2 & 176,1 & 104,7 & 162,4 & 33,8 & 8,2 & 25,6 & $1.317,0$ \\
1995 & 30,0 & 24,2 & 44,1 & 106,0 & 165,1 & 126,6 & 194,1 & 106,4 & 59,0 & 15,2 & 147,9 & 20,4 & $1.039,0$ \\
1996 & 64,6 & 32,2 & 33,6 & 238,6 & 102,2 & 265,6 & 83,6 & 184,6 & 119,3 & 41,6 & 131,6 & 24,4 & $1.321,9$ \\
1997 & 49,9 & 125,4 & 202,4 & 240,0 & 411,3 & 154,5 & 99,9 & 98,3 & 3,8 & 11,4 & 7,6 & 15,2 & $1.419,7$ \\
\hline MÉDIAS & 51,6 & 84,0 & 87,6 & 141,7 & 161,5 & 227,9 & 143,3 & 131,3 & 101,3 & 37,0 & 70,2 & 27,0 & - \\
\hline
\end{tabular}

TABELA 2 - Médias de produtividade e de peso médio de fruto da laranjeira 'Pêra' D6 enxertada sobre cinco porta-enxertos, no período de 19931997. Embrapa Tabuleiros Costeiros. Umbaúba-SE

\begin{tabular}{|c|c|c|c|c|c|c|c|c|c|c|c|c|}
\hline Porta-enxerto & 1993 & 1994 & 1995 & 1996 & 1997 & Acumulada & 1993 & 1994 & 1995 & 1996 & 1997 & Médias \\
\hline 'Cravo' & $34,3 \mathrm{a}$ & $47,6 \mathrm{~b}$ & $21,5 \mathrm{ab}$ & $34,9 \mathrm{ab}$ & $76,0 \mathrm{a}$ & $42,9 \mathrm{a}$ & $192,2 \mathrm{~b}$ & $227,3 \mathrm{ab}$ & $214,3 \mathrm{a}$ & $146,2 \mathrm{a}$ & $242,4 \mathrm{a}$ & $204,5 \mathrm{ab}$ \\
\hline 'Rugoso' & $18,3 \mathrm{~b}$ & $58,2 \mathrm{a}$ & $15,5 \mathrm{bc}$ & $35,5 \mathrm{ab}$ & $85,0 \mathrm{a}$ & $42,5 \mathrm{a}$ & $237,7 \mathrm{a}$ & $250,0 \mathrm{a}$ & $227,8 \mathrm{a}$ & $153,8 \mathrm{a}$ & $252,4 \mathrm{a}$ & 224,3 a \\
\hline 'Palermo' & $28,5 \mathrm{ab}$ & 49,9 ab & $19,3 \mathrm{abc}$ & $40,1 \mathrm{a}$ & $82,5 \mathrm{a}$ & $44,1 \mathrm{a}$ & $186,5 \mathrm{~b}$ & $222,3 a b c$ & $165,2 \mathrm{a}$ & $169,5 \mathrm{a}$ & $251,4 \mathrm{a}$ & $199,0 \mathrm{~b}$ \\
\hline 'Catânia 2' & $26,7 \mathrm{ab}$ & $50,8 \mathrm{ab}$ & $22,7 \mathrm{a}$ & $30,1 \mathrm{~b}$ & $82,4 \mathrm{a}$ & $42,5 \mathrm{a}$ & $189,6 \mathrm{~b}$ & $195,2 \mathrm{c}$ & $200,4 \mathrm{a}$ & $152,1 \mathrm{a}$ & $236,2 \mathrm{a}$ & 194,7 b \\
\hline 'Cleópatra' & $18,2 \mathrm{~b}$ & $57,0 \mathrm{a}$ & $13,6 \mathrm{c}$ & $27,4 \mathrm{~b}$ & $74,3 \mathrm{a}$ & $38,1 \mathrm{a}$ & $185,0 \mathrm{~b}$ & 204,7 bc & $208,5 \mathrm{a}$ & $141,0 \mathrm{a}$ & $226,5 \mathrm{a}$ & $193,1 \mathrm{~b}$ \\
\hline D.M.S. & 16,0 & 9,0 & 6,8 & 8,5 & 20,5 & 9,0 & 37,1 & 31,4 & 94,1 & 33,7 & 41,8 & 24,5 \\
\hline C. V. $(\%)$ & 22,4 & 6,0 & 13,0 & 8,9 & 9,1 & 9,1 & 6,6 & 5,1 & 16,4 & 7,8 & 6,1 & 9,2 \\
\hline
\end{tabular}

(*) Nas colunas, médias seguidas da mesma letra não diferem entre si, pelo teste de Tukey $(\mathrm{P}<0,05)$.

colocações. As seleções do ‘Volkameriano’, Palermo e Catânia 2 também apresentaram igual comportamento produtivo, exceto em 1993 e 1996, quando o 'Palermo' superou o 'Catânia 2'. Esses porta-enxertos, apesar de não diferirem significativamente da tangerineira 'Cleópatra' no período de 1993-97, apresentaram maiores produtividades acumuladas: 'Palermo' mais 29,8 t/ha (15,6\%) e 'Catânia 2' mais 22,2 t/ha (11,7\%). Com relação ao 'Cravo' e ao 'Rugoso', mesmo não diferindo estatisticamente, a 'Cleópatra' produziu $12 \%$ menos que a média de produção no período, ou seja, foi inferior em 22,9 $\mathrm{t}$ (Tabela 2). Na Bahia, em solo de Tabuleiro Costeiro, de textura média, segundo Cunha Sobrinho et al. (1980), a 'Cleópatra' induziu, significativamente, igual vigor e produtividade à copa de 'Pêra', quando comparada ao 'Cravo' e 'Rugoso'. Nesse mesmo solo, Cunha Sobrinho (1992) constatou que a 'Cleópatra' sob copa de laranjeira 'Baianinha' $C$. sinensis (L.) Osb., embora com início de produção menos precoce que o 'Cravo' e o 'Rugoso', igualou-se ao primeiro a partir dos 12 e até aos 15 anos de idade. Por outro lado, comparando-se a produtividade acumulada do $5^{\circ}$ ao $15^{\circ}$ ano do plantio, a 'Cleópatra' foi inferior ao 'Cravo' - $11,2 \%$ e ao 'Rugoso' - 30,6\%. Resultados semelhantes obtiveram Soares Filho et al. (1980) estudando porta-enxertos para laranjeira 'Natal' C. sinensis (L.) Osb., nas mesmas condições do experimento anterior. Essa tendência de produção também foi encontrada por Figueiredo (1985), quando informa que em solos arenosos a 'Cleópatra' produziu menos que o 'Cravo'. Todavia, segundo Donadio et al. (1993), a 'Cleópatra' enxertada com 'Pêra', nas condições de Bebedouro-SP, apresentou maior produtividade quando no espaçamento $7 \mathrm{~m} \times 2 \mathrm{~m}$, em período seco, contrariando as expectativas de ser mais sensível à seca que o 'Cravo'. Esses autores também informam que as "produções iniciais da 'Cleópatra' foram muito baixas, só atingindo um nível razoável no $5^{\circ}$ ano de plantio".
Os frutos da 'Pêra' sobre 'Rugoso' apresentaram maior peso médio que os originados sobre 'Palermo', 'Catânia 2' e 'Cleópatra', mas não diferiram significativamente dos produzidos sobre 'Cravo' (Tabela 2).

Os porta-enxertos não diferiram significativamente quanto à porcentagem de suco, mas o ‘Cravo' e a 'Cleópatra' apresentaram tendência para induzir a produção de frutos mais suculentos (Tabela 3). Estimandose o volume de suco, em t/ha, produzido no período de 1993-97, em cada combinação, obteve-se: 'Cravo' - 26.0, 'Palermo' - 24.9, 'Catânia 2'-24.0, 'Rugoso' - 23.8 e 'Cleópatra' - 23.2 t/ha. Esses resultados demonstram que a 'Cleópatra', apesar de não diferir estatisticamente, ofereceu maior rendimento de suco que o 'Rugoso', compensando a sua menor produção de frutos (Tabelas 2 e 3). Com relação à percentagem de suco, Donadio et al. (1993) obtiveram valores pouco maiores para o 'Cravo' em relação à 'Cleópatra' (plantas com 8-9 anos), respectivamente, 55 e 51\%, diferentes dos 60,7 e 61\% apresentados na Tabela 3; no entanto, registraram ocorrência de secas, o que contrasta com as boas precipitações ocorridas durante o presente estudo (Tabela 1).

Na Tabela 4, as médias do período de 1993-97 mostraram que a combinação com 'Rugoso' apresentou maior volume de copa, sem diferir significativamente do 'Cravo', 'Cleópatra' e 'Palermo', diferindo apenas do 'Catânia 2', que apresentou o menor volume de copa. As combinações apresentaram diferentes taxas de desenvolvimento vegetativo no período: 'Cleópatra' - 79,7\%; 'Rugoso' - 52,3\%; 'Catânia 2' - 51,2\%; 'Cravo' 48,3\% e 'Palermo' - 44,2\%, demonstrando o maior desenvolvimento vegetativo da 'Cleópatra', seguida do 'Rugoso'. O maior volume de copa da 'Cleópatra', em relação ao 'Cravo', também foi encontrado por Donadio et al. (1993). No que tange à produção de frutos por volume de copa, os porta-enxertos apresentaram diferenças significativas, com destaque para

TABELA 3 - Percentagem média de suco de frutos de laranjeira- 'Pêra' D6 sobre cinco porta-enxertos, no período de 1993-1997. Embrapa Tabuleiros Costeiros. Umbaúba-SE

\begin{tabular}{ccccccc}
\hline \multirow{2}{*}{ Porta-enxertos } & 1993 & 1994 & 1995 & 1996 & 1997 & Médias \\
\cline { 2 - 6 } & & & & $\%$ & & \\
\hline 'Cravo' & 58,6 & 61,6 & 65,4 & 60,1 & 57,6 & 50,7 a \\
'Rugoso' & 57,3 & 57,3 & 50,8 & 59,5 & 55,1 & 56,0 a \\
'Palermo' & 53,4 & 54,5 & 63,3 & 58,1 & 53,6 & 56,6 a \\
'Catânia 2' & 56,0 & 57,3 & 57,7 & 56,8 & 54,4 & 56,4 a \\
'Cleópatra' & 57,2 & 58,6 & 65,0 & 62,1 & 61,9 & 61,0 a \\
\hline
\end{tabular}

D.M.S.: 5,65; C. V. (\%): 5,02\%, para médias do período de 1993-97.

(*) Médias seguidas da mesma letra não diferem entre si, pelo teste de Tukey $(\mathrm{P}<0,05)$. 
TABELA 4 - Volume médio de copa e índice médio de eficiência da laranjeira- ‘Pêra' D6 ( $\mathrm{kg}$ de frutos/m³ de copa), em 1993, 95 e 97. Embrapa Tabuleiros Costeiros. Umbaúba-SE

\begin{tabular}{|c|c|c|c|c|c|c|c|c|}
\hline \multirow[t]{2}{*}{ Porta-enxertos } & \multicolumn{4}{|c|}{ Volume médio de copa $\left(\mathrm{m}^{3}\right)$} & \multicolumn{4}{|c|}{ Índice de eficiência $\left(\mathrm{kg} / \mathrm{m}^{3}\right)$} \\
\hline & 1993 & 1995 & 1997 & Médias & 1993 & 1995 & 1997 & Médias \\
\hline 'Cravo' & $20,9 \mathrm{ab}$ & $28,2 \mathrm{ab}$ & $31,0 \mathrm{a}$ & $26,7 \mathrm{a}$ & $40,4 \mathrm{a}$ & $18,6 \mathrm{~b}$ & $59,3 \mathrm{a}$ & $39,4 \mathrm{ABC}$ \\
\hline 'Rugoso' & $22,5 \mathrm{a}$ & $30,3 \mathrm{a}$ & $34,3 \mathrm{a}$ & $29,0 \mathrm{a}$ & $19,7 \mathrm{~b}$ & $12,3 \mathrm{c}$ & $60,1 \mathrm{a}$ & $30,7 \mathrm{C}$ \\
\hline 'Palermo' & $20,1 \mathrm{ab}$ & $25,0 \mathrm{bc}$ & $29,0 \mathrm{a}$ & $24,7 \mathrm{ab}$ & $34,5 \mathrm{ab}$ & $18,9 \mathrm{~b}$ & $69,5 \mathrm{a}$ & $41,0 \mathrm{AB}$ \\
\hline 'Catânia 2' & $18,4 \mathrm{~b}$ & $22,0 \mathrm{c}$ & $27,9 \mathrm{a}$ & $22,8 \mathrm{~b}$ & $35,5 \mathrm{ab}$ & $25,2 \mathrm{a}$ & $72,5 \mathrm{a}$ & $44,4 \mathrm{~A}$ \\
\hline 'Cleópatra' & $18,4 \mathrm{~b}$ & $25,1 \mathrm{bc}$ & $33,1 \mathrm{a}$ & $25,5 \mathrm{ab}$ & $25,6 \mathrm{ab}$ & $13,3 \mathrm{c}$ & $57,3 \mathrm{a}$ & $32,1 \mathrm{BC}$ \\
\hline D.M.S. & 2,8 & 4,6 & 7,3 & 4,4 & 17,8 & 4,1 & 19,6 & 9,9 \\
\hline C. V. $(\%)$ & 5,0 & 6,2 & 8,3 & 4,8 & 20,3 & 8,3 & 10,9 & 13,8 \\
\hline
\end{tabular}

(*) Na coluna, médias seguidas da mesma letra (minúscula - 5\% e maiúscula - 1\%) não diferem entre si, pelo teste de Tukey.

TABELA 5 - Características tecnológicas de sucos de frutos de laranjeira- 'Pêra' D6 sobre cinco porta-enxertos, no período de 1994-97. Embrapa Tabuleiros Costeiros. Umbaúba-SE

\begin{tabular}{|c|c|c|c|c|c|c|c|c|c|c|c|c|c|c|c|}
\hline \multirow{2}{*}{$\begin{array}{l}\text { Porta - } \\
\text { enxertos }\end{array}$} & \multicolumn{5}{|c|}{ SST $\left({ }^{\circ}\right.$ Brix $)$} & \multicolumn{5}{|c|}{ ATT (\%) } & \multicolumn{5}{|c|}{ SST/ATT ( ratio) } \\
\hline & 1994 & 1995 & 1996 & 1997 & Médias & 1994 & 1995 & 1996 & 1997 & Médias & 1994 & 1995 & 1996 & 1997 & Média \\
\hline 'Cravo' & 11,2 & 12,0 & 11,6 & 10,3 & $11,3 \mathrm{a}$ & 0,6 & 0,5 & 0,6 & 0,6 & $0,6 \mathrm{ab}$ & 20,1 & 25,6 & 19,1 & 16,8 & $20,4 a b$ \\
\hline 'Rugoso' & 10,8 & 11,0 & 10,8 & 9,8 & $10,6 \mathrm{a}$ & 0,6 & 0,5 & 0,7 & 0,6 & $0,6 \mathrm{a}$ & 18,0 & 21,2 & 16,1 & 15,3 & $17,6 \mathrm{~b}$ \\
\hline 'Palermo' & 10,8 & 11,1 & 11,2 & 10,2 & $10,8 \mathrm{a}$ & 0,5 & 0,4 & 0,5 & 0,6 & $0,5 \mathrm{~b}$ & 20,4 & 27,1 & 21,2 & 17,2 & $21,5 \mathrm{a}$ \\
\hline 'Catânia 2' & 11,7 & 12,0 & 11,3 & 10,1 & $11,3 \mathrm{a}$ & 0,5 & 0,4 & 0,6 & 0,6 & $0,6 \mathrm{ab}$ & 22,1 & 27,3 & 19,1 & 16,3 & $21,2 \mathrm{a}$ \\
\hline 'Cleópatra' & 11,2 & 11,0 & 11,5 & 10,8 & $11,1 \mathrm{a}$ & 0,6 & 0,4 & 0,6 & 0,6 & $0,5 \mathrm{ab}$ & 17,8 & 29,0 & 19,1 & 19,3 & $21,3 \mathrm{a}$ \\
\hline
\end{tabular}

SST - sólidos solúveis totais; ATT - acidez total titulável.

(*) Na coluna, médias seguidas da mesma letra não diferem entre si, pelo teste de Tukey $(\mathrm{P}<0,05)$.

o 'Catânia 2', que diferiu da ‘Cleópatra' e do 'Rugoso', enquanto o 'Cravo', 'Cleópatra' e 'Rugoso' não diferiram entre si, mas apenas este último diferiu do 'Palermo' (Tabela 4).

Quanto aos teores de sólidos solúveis totais (SST), acidez total titulada (ATT) e relação SST/ATT "ratio", apresentados na Tabela 5, os porta-enxertos apresentaram variações significativas, apenas para ATT e "ratio". Não se observou diferença significativa entre as combinações com relação ao teor de sólidos solúveis, embora o 'Cravo' e o 'Catânia 2' tenham induzido aos frutos maiores teores de açúcar. Nesse sentido, Soares Filho et al. (1980) apresentaram resultados com tendência semelhante quando informaram que o 'Cravo' sob copa de 'Natal' induziu a formação de frutos com teores mais elevados de açúcares que o 'Rugoso'. Neste estudo, com relação à acidez total, o 'Rugoso' apenas diferiu do 'Palermo', mas ambos não diferiram dos demais porta-enxertos. Quanto à relação SST/ATT, os porta-enxertos apresentaram pequenas variações, mas apenas o 'Rugoso' diferiu do 'Palermo', 'Catânia 2' e 'Cleópatra', enquanto os demais não diferiram entre si. Donadio et al. (1993), comparando o 'Cravo' à 'Cleópatra', informaram que, para a qualidade do fruto de 'Pêra', não houve diferença entre eles; também Cunha Sobrinho (1992), comparando dados de SST, ATT e relação SST/ATT, obteve resultados semelhantes com laranja 'Baianinha' sobre 'Cravo', 'Rugoso' e 'Cleópatra', exceto com relação à SST/ATT, quando informou que o 'Rugoso' não diferiu da 'Cleópatra'.

Com relação aos problemas fitossanitários, não se observou a ocorrência da gomose de Phytophthora e do declínio dos citros nas diferentes combinações copa/porta-enxertos. A incompatibilidade entre 'Volkameriano' e 'Pêra' não foi constatada através de inspeções na região da enxertia.

\section{CONCLUSÕES}

As seleções do limoeiro 'Volkameriano', 'Palermo' e 'Catânia 2', e a tangerineira 'Cleópatra' apresentaram comportamento semelhante aos limoeiros 'Cravo' e 'Rugoso da Flórida', os mais utilizados nas regiões citrícolas de Sergipe e do litoral norte da Bahia.

\section{REFERÊNCIAS BIBLIOGRÁFICAS}

CINTRA, F.L.D. Disponibilidade de água no solo para porta-enxertos de citros em ecossistema de tabuleiro costeiro. 1997. 100f: Tese
(Doutorado em solos)- Escola Superior de Agricultura "Luiz de Queiroz", Universidade de São Paulo, Piracicaba, 1997.

CUNHA SOBRINHO, A.P. da. Comportamento de porta-enxertos cítricos sob as condições tropicais do recôncavo baiano. 1992. 89f. Dissertação (mestrado) - Escola Agronômica da Universidade Federal da Bahia, Cruz das Almas, 1992.

CUNHA SOBRINHO, A.P. da; SOARES FILHO, W. dos S.; PASSOS, O.S. Porta-enxertos para laranja 'Pêra' (Citrus sinensis (L) Osbeck) na região de Cruz das Almas, Bahia. Revista Brasileira de Fruticultura, Cruz das Almas, Bahia, v.2, n.3, p.21-32, 1980.

DONADIO, L.C.; CABRITA, J.R.M.; SEMPIONATO, O.R.; PARO, M. Tangerina 'Cleópatra': vantagens e desvantagens como portaenxerto na citricultura. Laranja, Cordeirópolis, v.14, n.2, p. 565-579, 1993.

FIGUEIREDO, J.O.; POMPEU JUNIOR, J.; RODRIGUEZ, O.; CAETANO, A.A.; ROCHA, T.R.; IGUE, T. Competição de dez porta-enxertos para a laranjeira Barão Citrus sinensis (L.) Osbeck. In: CONGRESSO BRASILEIRO DE FRUTICULTURA, 7., 1981, Recife, PE. Anais... Recife: RBF, 1981.v.2, p.501-516.

FIGUEIREDO, J.O. Porta-enxertos para citros. Laranja, Cordeirópolis, n. 6, p. 449-458, 1985

POMPEU JÚNIOR, J. Porta-enxertos para citros. In: RODRIGUEZ, O.; VIÉGAS, F.C.P.; POMPEU JÚNIOR, J.; AMARO, A.A. Citricultura brasileira. 2. Campinas: Fundação Cargill, 1991. p. 265-280.

POMPEU JÚNIOR, J.; FIGUEIREDO, J.O. de; TEÓFILO SOBRINHO, J.; JORGE, J. de P.N.; SALIBE, A.A. Porta-enxertos para laranja 'Hamlin'. In: CONGRESSO BRASILEIRO DE FRUTICULTURA, 4., 1977, Salvador. Anais... Cruz das Almas - BA: SBF, 1978. p.105-110.

SALIBE, A.A. Importância do porta-enxerto na citricultura. In: ENCONTRO NACIONAL DE FRUTICULTURA, 5., 1978, Rio de Janeiro, RJ. PESAGRO-RIO/SBF, 1987. 14p.

SOARES FILHO, W. dos S.; CUNHA SOBRINHO, A.P. da; PASSOS, O.S. Porta-enxertos para laranja 'Natal'. Pesquisa Agropecuária Brasileira, Brasília, v.15, n.4, p.471 - 474, 1980.

TRINDADE, J.; SILVA, L.M.S. da; SILVA, J.U.B.; MELO, M. de; SOBRAL, L.F. Formação e manutenção de pomar cítrico. Aracaju: EMPEASE, 1989. 24p. (Circular Técnica, 1). 